Article

\title{
Comprehensive Research of Total Ionizing Dose Effects in GaN-Based MIS-HEMTs Using Extremely Thin Gate Dielectric Layer
}

\author{
Sung-Jae Chang ${ }^{1, *}$, Dong-Seok Kim ${ }^{2}$, Tae-Woo Kim ${ }^{3}{ }^{\circledR}$, Jung-Hee Lee ${ }^{4}$, Youngho Bae ${ }^{5}$, \\ Hyun-Wook Jung ${ }^{1}$, Soo Cheol Kang ${ }^{1}{ }^{1}$, Haecheon Kim ${ }^{1}$, Youn-Sub Noh ${ }^{1}$, Sang-Heung Lee ${ }^{1}$, \\ Seong-Il Kim ${ }^{1}$, Ho-Kyun Ahn ${ }^{1}$ and Jong-Won Lim ${ }^{1}$ \\ 1 Defense Materials and Components, Convergence Research Department, Electronics and \\ Telecommunications Research Institute, Daejeon 34129, Korea; hujung@etri.re.kr (H.-W.J.); \\ kangsc817@etri.re.kr (S.C.K.); khc@etri.re.kr (H.K.); nohys@etri.re.kr (Y.-S.N.); shl@etri.re.kr (S.-H.L.); \\ sikim@etri.re.kr (S.-I.K.); hkahn@etri.re.kr (H.-K.A.); jwlim@etri.re.kr (J.-W.L.) \\ 2 Korea Multi-purpose Accelerator Complex, Korea Atomic Energy Research Institute, Gyungju 38180, Korea; \\ dongseokkim@kaeri.re.kr \\ 3 Department of Electrical/Electronic, University of Ulsan, Ulsan 44610, Korea; twkim78@ulsan.ac.kr \\ 4 School of Electronics and Electrical Engineering, Kyungpook National University, Daegu 41566, Korea; \\ jlee@ee.knu.ac.kr \\ 5 Department of IT convergence, Uiduk University, Gyeongju 38004, Korea; yhbae@uu.ac.kr \\ * Correspondence: sjchang@etri.re.kr; Tel.: +82-(42)-8606631
}

Received: 7 October 2020; Accepted: 27 October 2020; Published: 30 October 2020

check for updates

\begin{abstract}
The device performance deterioration mechanism caused by the total ionizing dose effect after the $\gamma$-ray irradiation was investigated in GaN-based metal-insulator-semiconductor high electron mobility transistors (MIS-HEMTs) for a $5 \mathrm{~nm}$-thick $\mathrm{SiN}$ and $\mathrm{HfO}_{2}$ gate dielectric layer. The $\gamma$-ray radiation hardness according to the gate dielectric layer was also compared between the two different $\mathrm{GaN}$-based MIS-HEMTs. Although $\mathrm{HfO}_{2}$ has exhibited strong tolerance to the total ionizing dose effect in Si-based devices, there is no detail report of the $\gamma$-ray radiation effects in GaN-based MIS-HEMTs employing a $\mathrm{HfO}_{2}$ gate dielectric layer. The pulsed-mode stress measurement results and carrier mobility behavior revealed that the device properties not only have direct current (DC) characteristics, but radio frequency $(\mathrm{RF})$ performance has also been mostly degraded by the deterioration of the gate dielectric quality and the trapped charges inside the gate insulator. We also figured out that the immunity to the $\gamma$-ray radiation was improved when $\mathrm{HfO}_{2}$ was employed instead of $\mathrm{SiN}$ as a gate dielectric layer due to its stronger endurance to the $\gamma$-ray irradiation. Our results highlight that the application of a gate insulator that shows superior immunity to the $\gamma$-ray irradiation is a crucial factor for the improvement of the total ionizing dose effect in GaN-based MIS-HEMTs.
\end{abstract}

Keywords: $\mathrm{GaN}$; $\mathrm{SiN}$; $\mathrm{HfO}_{2}$; gate insulator; MIS-HEMT; total ionizing dose effect; $\gamma$-ray; radiation

\section{Introduction}

Gallium nitride based high electron mobility transistors (HEMTs) have been intensively studied for high frequency, high power, low noise, and aerospace applications thanks to its wide bandgap, high breakdown electric field, high carrier density, and high carrier mobility at the hetero-interface [1,2]. However, there are many dangling bonds at the AlGaN surface, which trap negative charges. The negative trapped charges cause the reduction of the 2-dimensional electron gas (2DEG) density and degradation of the radio frequency $(\mathrm{RF})$ performance that is known as the current collapse effects $[3,4]$. The lack of the gate insulator results in the high gate current and limitation of the current driving 
due to the gate Schottky contact in GaN-based HEMTs [5-8]. To deal with these issues, GaN-based metal-insulator-semiconductor (MIS)-HEMTs have been proposed. The dielectric layer deposited on top of the barrier (or capping) layer improves the radio frequency (RF) performance by diminishing the current collapse when it is utilized as a surface passivation $[3,4]$. When the dielectric layer is used as a gate insulator, the gate leakage is reduced $[5,6]$ and the current driving capacity is improved $[7,8]$. However, there are side effects of the gate insulator, which are the transconductance reduction and degradation of RF performance. Therefore, a thin insulator that shows sufficient quality as a gate dielectric layer is required. From this point of view, various gate insulator materials [9-15] and multi-layered dielectric structures [16,17] have been investigated in GaN-based MIS-HEMTs.

For aerospace applications of the GaN-based MIS-HEMTs, the radiation effects on the device characteristics have been researched for various gate dielectric layers such as $\mathrm{SiN}$ [18], $\mathrm{SiO}_{2}$ [19], $\mathrm{Al}_{2} \mathrm{O}_{3}$ [20], $\mathrm{MgCaO}$ [21], $\mathrm{Gd}_{2} \mathrm{O}_{3}$ [22], and $\mathrm{SiN} / \mathrm{Al}_{2} \mathrm{O}_{3}$ multi-layered gate insulators [23]. The radiation hardness of the gate insulator is weaker than that of AlGaN and $\mathrm{GaN}$ in GaN-based MIS-HEMTs. The degradation of the dielectric quality and trapped charges inside the dielectric layer (and/or at the dielectric interface), which is the total ionizing dose (TID) effects generated by the radiation, deteriorate direct current (DC) and RF performance of the devices. As the radiation hardness strongly depends on the gate dielectric layer in GaN-based MIS-HEMTs [21-23], the device performance degradation mechanism caused by the radiation exposure and the impact of the gate insulator on the device radiation hardness are still not clear in many cases. Therefore, it is necessary to investigate the TID effects induced by $\gamma$-ray irradiation on the device characteristics in GaN-based MIS-HEMTs, since this results in the degradation of the dielectric layer quality rather than $\mathrm{AlGaN}$ and $\mathrm{GaN}$ [24].

In this work, we focused on the TID effects in GaN-based MIS-HEMTs for a $5 \mathrm{~nm}$-thick $\mathrm{HfO}_{2}$ gate dielectric layer for the minimization of the transconductance and RF performance degradation. To the best of our knowledge, the $\gamma$-ray radiation effect has not been reported in GaN-based MIS-HEMTs for the $\mathrm{HfO}_{2}$ gate insulator thus far, even though $\mathrm{HfO}_{2}$ exhibited excellent radiation hardness in Si-based electronics $[25,26]$. After $\gamma$-ray radiation, the DC and RF performance deterioration were investigated via electrical characterization. GaN-based MIS-HEMTs for a $\mathrm{HfO}_{2}$ gate dielectric layer demonstrated superior immunity to the $\gamma$-ray irradiation compared to the $\mathrm{SiN}$ gate insulator. In comparison with the $\mathrm{SiN}$ gate dielectric layer, when $\mathrm{HfO}_{2}$ was employed, the threshold voltage $\left(V_{\mathrm{TH}}\right)$ shift $\left(\Delta V_{\mathrm{TH}}\right)$, transconductance $\left(g_{\mathrm{m}}\right)$ maximum deterioration $\left(\Delta g_{\mathrm{m}, \max }\right)$, drain current $\left(I_{\mathrm{D}}\right)$, and reduction $\left(\Delta I_{\mathrm{D}}\right)$ were improved from 0.15 to $0.075 \mathrm{~V}, 5.42$ to $2.27 \%$, and 5.40 to $2.31 \%$, respectively. The pulse-mode stress measurements and extracted carrier mobility $(\mu)$ behavior revealed that the degradation of the gate dielectric quality and trapped charges inside the gate dielectric layer was the origin of the degradation in device performance in terms of $\Delta V_{\mathrm{TH}}, \Delta g_{\mathrm{m} \text {,max }}$, and $\Delta I_{\mathrm{D}}$. The RF performance degradation was also improved with the $\mathrm{HfO}_{2}$ gate insulator compared to the SiN. The cut-off frequency $\left(f_{\mathrm{T}}\right)$ and maximum oscillation frequency $\left(f_{\mathrm{MAX}}\right)$ degradation were improved from 36.14 to $13.3 \%$ and 34.52 to $10.68 \%$, respectively. Our systematic measurements revealed that the $\mathrm{HfO}_{2}$ gate insulator showed excellent immunity to the $\gamma$-ray radiation and is suitable for aerospace electronics compared to the $\mathrm{SiN}$ dielectric layer.

\section{Structure and Fabrication}

The GaN-based MIS-HEMTs were fabricated on a sapphire substrate. The epitaxial layers were grown by metal-organic chemical vapor deposition, which were composed of a $2 \mu \mathrm{m}$-thick GaN buffer, $50 \mathrm{~nm}$-thick $\mathrm{GaN}$ channel, and $20 \mathrm{~nm}$-thick $\mathrm{Al}_{0.25} \mathrm{Ga}_{0.75} \mathrm{~N}$ barrier layers. Ti/Al/Ni/Au (30/100/30/100 nm) were deposited followed by rapid thermal annealing at $850^{\circ} \mathrm{C}$ for $40 \mathrm{~s}$ for Ohmic contact formation. For the device isolation, phosphorus was implanted. In order to compare the endurance of the $\gamma$-ray radiation and study the device performance degradation mechanism, two different gate dielectric layers (Sample-SiN: SiN 5 nm-thick; Sample- $\mathrm{HfO}_{2}$ : $\mathrm{HfO}_{2} 5 \mathrm{~nm}$-thick) were prepared. A SiN layer and $\mathrm{HfO}_{2}$ layer were deposited by chemical vapor deposition (CVD) and atomic layer deposition (ALD), respectively. The areas to form the source and drain contact pads were opened through buffered oxide 
etch. Ni/Au (30/370 nm) were deposited for gate electrode as well as source and drain contact pads. The gate length $\left(L_{\mathrm{G}}\right)$, gate width $\left(W_{\mathrm{G}}\right)$, and the distance between the source and gate $\left(L_{\mathrm{SG}}\right)$, and gate and drain $\left(L_{\mathrm{GD}}\right)$ of the processed devices were $0.5,100,1$, and $3.5 \mu \mathrm{m}$, respectively. The radiated $\gamma$-ray doses were $0.3,0.9,1.8$, and $3.6 \mathrm{Mrad}\left(\mathrm{SiO}_{2}\right)$ with the dose rate of $50 \mathrm{rad} / \mathrm{s}$, which were irradiated at the Advanced Radiation Technology Institute. After each $\gamma$-ray irradiation, the same device was measured for various electrical measurement. However, there was no hysteresis and/or history effects between the different measurements. Figure 1 shows the schematic cross-section of the fabricated GaN-based MIS-HEMTs.

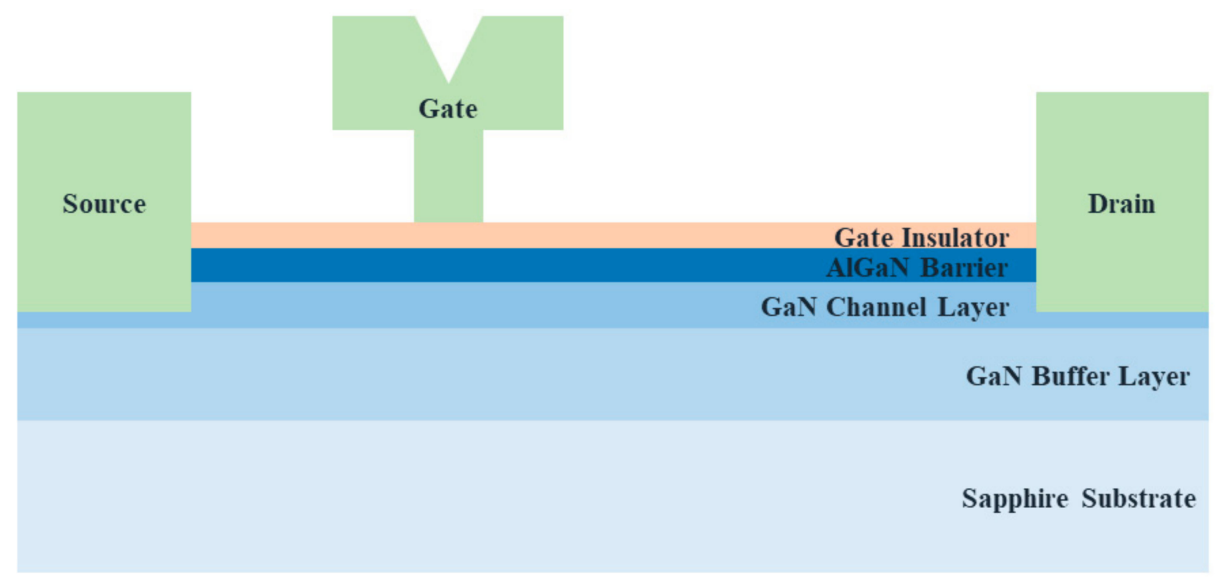

Figure 1. Schematic cross-section of the processed GaN-based metal-insulator-semiconductor high electron mobility transistors (MIS-HEMTs). A 5 nm-thick $\mathrm{SiN}$ and $\mathrm{HfO}_{2}$ layer were employed for Sample-SiN and- $\mathrm{HfO}_{2}$, respectively, as a gate dielectric layer.

\section{Results and Discussion}

The alteration of the typical device characteristics produced by the $\gamma$-ray irradiation was measured in the GaN-based MIS-HEMTs for the two samples in Figure 2. The drain current and gate leakage current were measured at drain bias (i.e., applied voltage at drain electrode, $\left.V_{\mathrm{D}}\right)=0.5 \mathrm{~V}$ while the gate bias (i.e., applied voltage at gate electrode, $V_{\mathrm{G}}$ ) was swept from -6.5 to $0 \mathrm{~V}$ and $-6 \mathrm{~V}$ to $0 \mathrm{~V}$ for Sample-SiN and Sample- $\mathrm{HfO}_{2}$, respectively. The transconductance was obtained by the derivation of the drain current. The difference of the device properties such as $V_{\mathrm{TH}}, I_{\mathrm{D}}$, and $g_{\mathrm{m}}$ in fresh devices (i.e., before the $\gamma$-ray radiation) comes primarily from the electrical thickness of the gate dielectric layer [16]. The $V_{\mathrm{TH}}$ was negatively shifted and $g_{\mathrm{m}}$ and $I_{\mathrm{D}}$ were reduced after the $\gamma$-ray irradiation in Sample-SiN. Moreover, in Sample-SiN, the $\Delta V_{\mathrm{TH}}, \Delta g_{\mathrm{m}, \max }$, and $\Delta I_{\mathrm{D}}$ were enlarged with an increase in the irradiated $\gamma$-ray doses. In comparison, the device characteristics barely changed after the $\gamma$-ray irradiation with the doses of 3.6 Mrad in Sample- $\mathrm{HfO}_{2}$, which indicates stronger $\gamma$-ray radiation endurance in Sample- $\mathrm{HfO}_{2}$. The gate leakage currents were remained almost unchanged after $\gamma$-ray irradiation for the two samples. Therefore, the gate electrode was unaffected by the $\gamma$-ray radiation.

To quantify the device property change induced by the $\gamma$-ray radiation and for the precise comparison of the radiation hardness according to the gate dielectric layer, various device parameters in terms of $\Delta V_{\mathrm{TH}}, \Delta g_{\mathrm{m}, \max }$, and $\Delta I_{\mathrm{D}}$ were extracted, as shown in Figure 3. The device parameters were achieved at $V_{\mathrm{D}}=0.5 \mathrm{~V}$ for the minimization of the lateral electric field effect caused by the drain bias. The observed overall tendencies of the device parameter variation were identical for the three parameters. However, almost half of the device property alternation was obtained in Sample- $\mathrm{HfO}_{2}$ compared to Sample-SiN, despite the epitaxial structure and physical thickness of the gate insulator being the same for the two samples. This phenomenon reflects that the DC performance change resulted from the $\gamma$-ray radiation was severely dominated by the gate dielectric property and $\mathrm{HfO}_{2}$ showed stronger immunity to the $\gamma$-ray radiation than that of $\mathrm{SiN}$. The clues to the device performance 
variation and the reason for the lower parameter change in Sample- $\mathrm{HfO}_{2}$ are described with the pulse-mode measurement results and carrier mobility behavior.
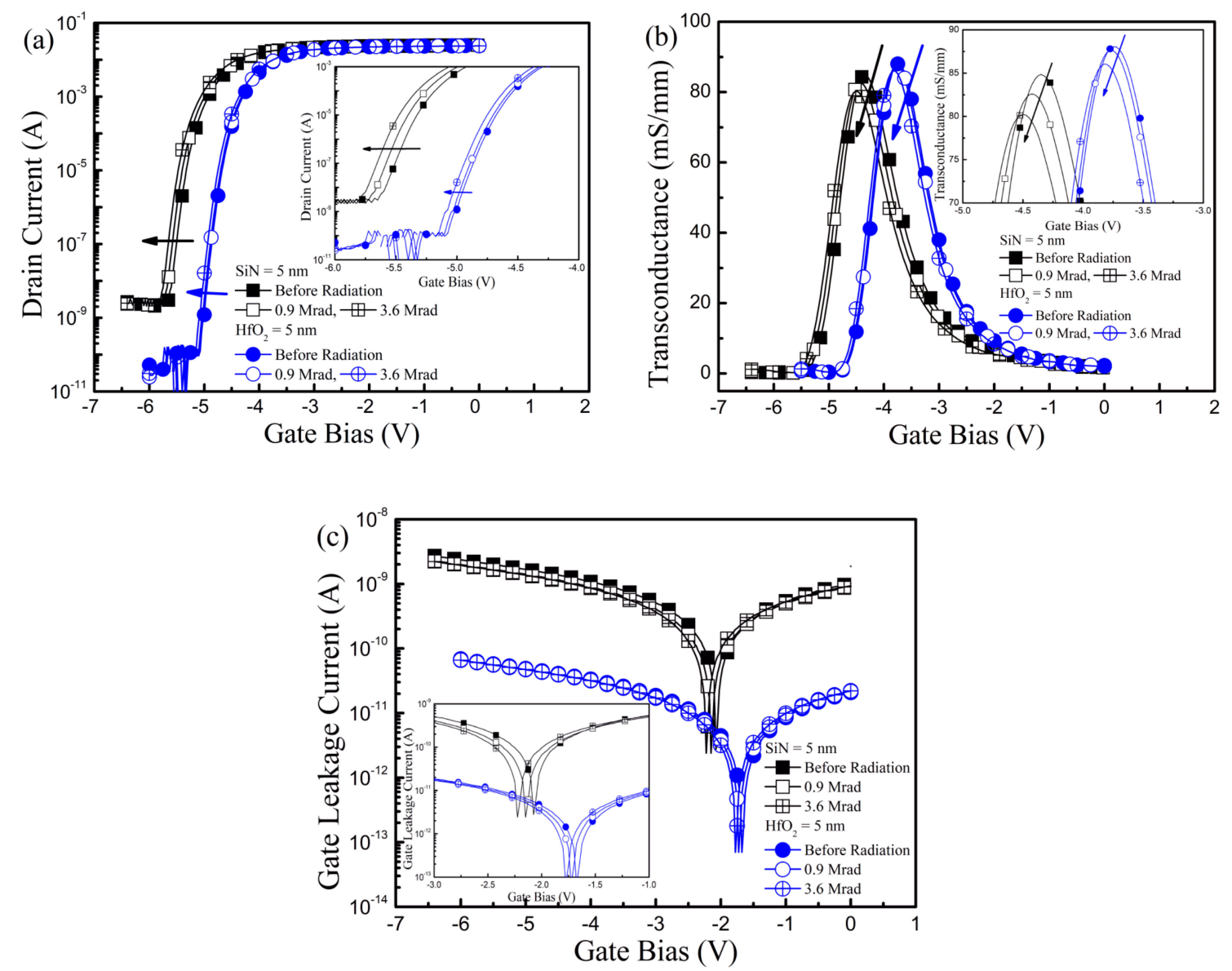

Figure 2. Transfer characteristics of the GaN-based MIS-HEMTs for a 5 nm-thick $\mathrm{SiN}$ and $\mathrm{HfO}_{2}$ gate dielectric layer before and after $\gamma$-ray radiation with the doses of 0.9 and 3.6 Mrad. (a) Drain current; (b) transconductance; (c) gate leakage current as a function of gate bias. Inset in Figure 2a-c shows the zoomed-in drain current at the subthreshold regime, transconductance near the transconductance maximum, and gate leakage current near the gate leakage minimum, respectively.

In Figure 4, the capacitance-voltage $\mathrm{C}(\mathrm{V})$ measurements before and after the $\gamma$-ray radiation was conducted at $1 \mathrm{MHz}$ for the two samples. The capacitance was measured while the gate bias was swept like that for the drain current measurement in Figure 2a. After the $\gamma$-ray radiation, the capacitance curves were negatively shifted, which was caused by the variation in the channel electron concentration after the $\gamma$-ray radiation. However, the shift was less in Sample- $\mathrm{HfO}_{2}$ than in Sample-SiN.

To achieve the key factor of the $\Delta V_{\mathrm{TH}}$ and clues to the stronger radiation hardness of the $\mathrm{HfO}_{2}$ layer than $\mathrm{SiN}$, pulse-mode stress measurements [16,27] were carried out, as shown in Figure 5. When the pulse-mode stress is provided, the charges are trapped in the GaN-based MIS-HEMTs [16]. The trapped charges change the carrier density at the AlGaN/GaN hetero-interface and threshold voltage. For the pulse-mode measurements, the drain current was measured at $V_{\mathrm{G}}=V_{\mathrm{TH}}+2 \mathrm{~V}$ when the pulses applied at drain electrode increased from $0 \mathrm{~V}$ to $10 \mathrm{~V}$. For the without stress, gate stress, and gate-and-drain stress condition, $\left(V_{\mathrm{G}}=0 \mathrm{~V}, V_{\mathrm{D}}=0 \mathrm{~V}\right),\left(V_{\mathrm{G}}=V_{\mathrm{TH}}-2 \mathrm{~V}, V_{\mathrm{D}}=0 \mathrm{~V}\right)$, and $\left(V_{\mathrm{G}}=V_{\mathrm{TH}}-2 \mathrm{~V}\right.$, $V_{\mathrm{D}}=10 \mathrm{~V}$ ) were applied as the quiescent biases, respectively, in the pulse-mode stress measurements. A 2 ms stress pulse was applied, followed by a $0.2 \mu$ s pulse to measure the drain current. 

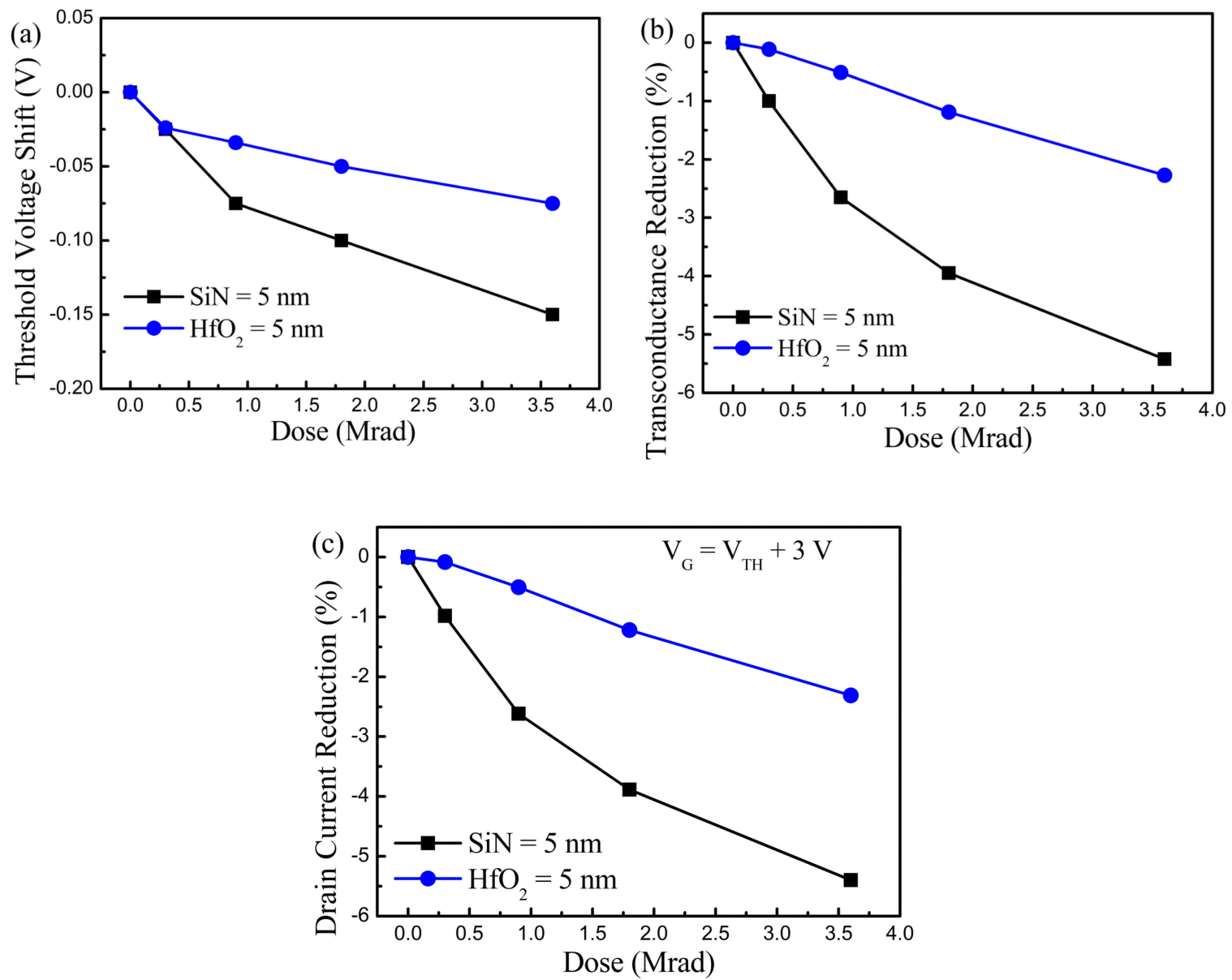

Figure 3. Extracted device parameters before and after the $\gamma$-ray irradiation in GaN-based MIS-HEMTs for a $5 \mathrm{~nm}$-thick $\mathrm{SiN}$ and $\mathrm{HfO}_{2}$ gate dielectric layer. (a) Threshold voltage shift; (b) transconductance maximum reduction; (c) drain current reduction vs. irradiated $\gamma$-ray doses.

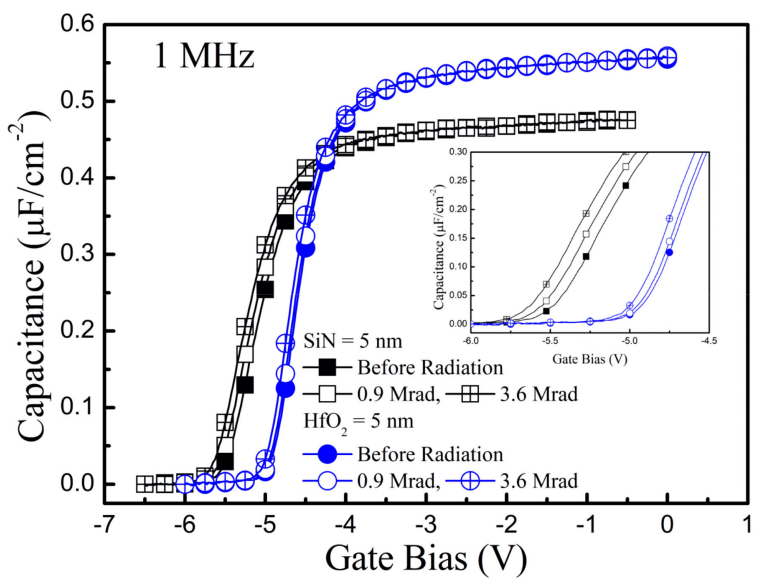

Figure 4. Capacitance-voltage measurements before and after the $\gamma$-ray irradiation in GaN-based MIS-HEMTs for a $5 \mathrm{~nm}$-thick $\mathrm{SiN}$ and $\mathrm{HfO}_{2}$ gate dielectric layer. 

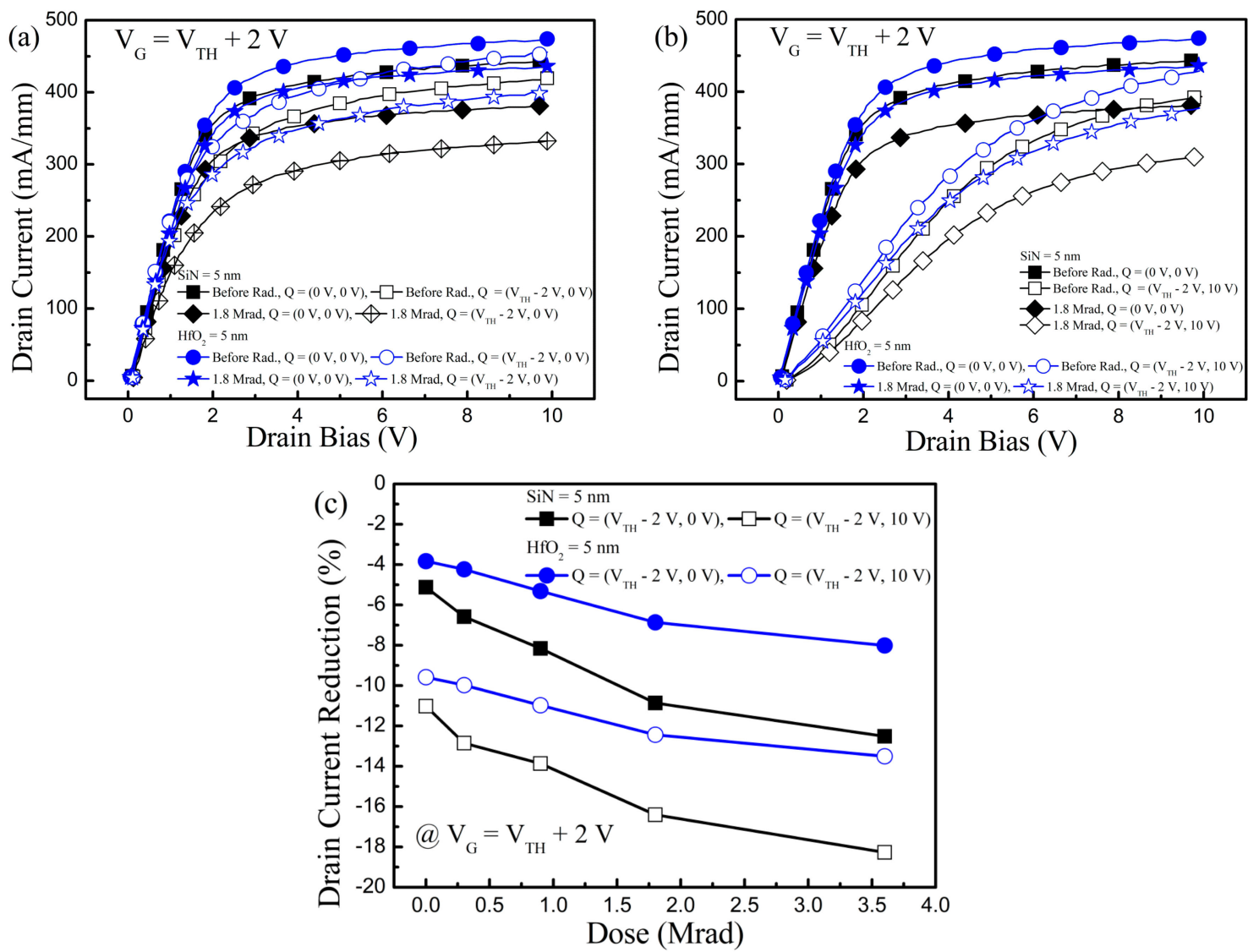

Figure 5. Pulse-mode stress measurement results. Drain current as a function of drain bias with the quiescent bias of: $(\mathbf{a})(0 \mathrm{~V}, 0 \mathrm{~V})$ and $\left(V_{\mathrm{TH}}-2 \mathrm{~V}, 0 \mathrm{~V}\right) ;(\mathbf{b})(0 \mathrm{~V}, 0 \mathrm{~V})$ and $\left(V_{\mathrm{TH}}-2 \mathrm{~V}, 10 \mathrm{~V}\right)$ before and after $\gamma$-ray radiation with the irradiated doses of $1.8 \mathrm{Mrad}$. (c) Drain current reduction from the quiescent bias of $(0 \mathrm{~V}, 0 \mathrm{~V})$ caused by the pulse-mode stress with the quiescent bias of $\left(V_{\mathrm{TH}}-2 \mathrm{~V}, 0 \mathrm{~V}\right)$ and $\left(V_{\mathrm{TH}}-2 \mathrm{~V}, 10 \mathrm{~V}\right)$ vs. irradiated $\gamma$-ray doses.

The $I_{\mathrm{D}}$ was lower than that of the without stress condition when the pulse-mode gate stress or gate-and-drain stress was applied [16,27]. Compared to the gate stress condition, the $\Delta I_{D}$ was lower under the gate-and-drain stress condition as the impact of traps existed at the GaN channel and/or buffer was included. With an increase in the irradiated $\gamma$-ray doses, the $\Delta I_{\mathrm{D}}$ was enlarged. In particular, the $\Delta I_{\mathrm{D}}$ distinction between the gate stress and gate-and-drain stress condition in Sample- $\mathrm{HfO}_{2}$ increased to $4.1 \%$ after $\gamma$-ray irradiation with doses of $3.6 \mathrm{Mrad}$, and was less than that of Sample-SiN (7.3\%). However, the $\Delta I_{\mathrm{D}}$ difference between the gate stress and gate-and-drain stress condition was maintained as the same for both samples. Even the $\Delta I_{\mathrm{D}}$ gap between the gate stress and gate-and-drain stress condition did not increase after the $\gamma$-ray irradiation in comparison with the $\Delta I_{\mathrm{D}}$ difference before the $\gamma$-ray irradiation. These results verified that the $\gamma$-ray irradiation mainly deteriorated the quality of the gate dielectric and generated the charge trapping centers mostly located in the interior of the gate insulator.

The $\gamma$-ray irradiation brought out identical results (i.e., negative $V_{\mathrm{TH}}$ shift) in Sample-SiN and Smaple- $-\mathrm{HfO}_{2}$, but the occasion was different according to the gate insulator in GaN-based MIS-HEMTs. The silicon-nitride dangling bond defects known as $K$ centers [28-30] exist in the SiN gate dielectric layer deposited by the CVD system. When the $\gamma$-ray is radiated, the neutral $K^{0}$ centers trap holes and are converted to positively charged $\mathrm{K}^{+}$defects [31]. The charge trapping mechanism of the $\mathrm{HfO}_{2}$ dielectric layer deposited by ALD is different from that of SiN. The $\gamma$-ray irradiation causes the bond breaking of the $\mathrm{HfO}_{2}$. The broken bonds in $\mathrm{HfO}_{2}$ result in the oxygen vacancy where there are trap holes [26]. As a result, the 2-dimensional electron gas (2DEG) density is increased by the trapped holes 
and the $V_{\mathrm{TH}}$ is negatively shifted. In SiN layer, there are many preexisting point defects (i.e., $K$ centers), which can trap holes and be transformed into the $K^{+}$defects [28-31]. Therefore, the Sample-SiN exhibited larger $\Delta V_{\mathrm{TH}}$ than in Sample- $\mathrm{HfO}_{2}$. The degradation of the gate insulator quality and the number of trapped holes were increased when the irradiated $\gamma$-ray doses increased, enlarging $\Delta V_{\mathrm{TH}}$ with an increase in $\gamma$-ray radiation.

To understand the $\Delta g_{\mathrm{m}, \max }$ and $\Delta I_{\mathrm{D}}$, the $\mu$ behavior was extracted before and after the $\gamma$-ray irradiation for the two samples, since the $g_{\mathrm{m}}$ and $I_{\mathrm{D}}$ are as a function of $\mu$ (Figure 6). Like the device parameter extraction, a drain bias of $0.5 \mathrm{~V}$ was applied to extract the $\mu$ behavior for the ignorance of the lateral field effect, which changes the carrier concentration and mobility behavior.
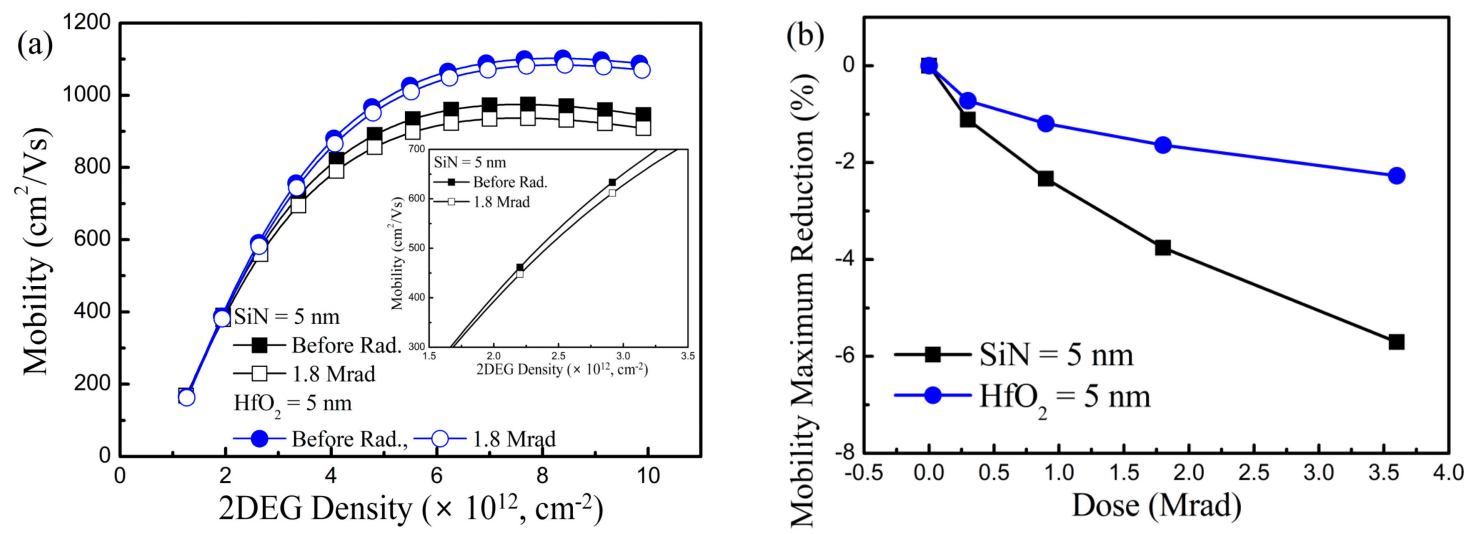

Figure 6. Carrier mobility deterioration according to the $\gamma$-ray radiation. (a) Carrier mobility as a function of 2DEG density before and after the $\gamma$-ray radiation with the doses of $1.8 \mathrm{Mrad}$. (b) Carrier mobility maximum reduction as a function of irradiated $\gamma$-ray doses. Inset in Figure 5a shows the zoomed-in carrier mobility behavior at low 2DEG density regime in Sample-SiN before and after the $\gamma$-ray radiation with doses of $1.8 \mathrm{Mrad}$.

The effect of the parasitic resistance of the access regions (between source and gate and gate and drain) and contact resistance was taken into account to achieve the accurate $\mu$ behavior under the gated region [32]. To extract the precise mobility behavior under the gated region, we used the following equation:

$$
\mu=\left[\left(I_{\mathrm{D}} / V_{\mathrm{D} \_\mathrm{MODIFIED}}\right) L_{\mathrm{G}}\right] /\left(q W_{\mathrm{G}} N_{\mathrm{s}}\right)
$$

where $N_{\mathrm{S}}$ is the electron concentration estimated by integrating the $\mathrm{C}(\mathrm{V})$ curve; $q$ is the electron charge; and $V_{\text {D_MODIFIED }}$ is the drain voltage across the gated channel, as shown in Equation (2):

$$
V_{\mathrm{D} \_\mathrm{MODIFIED}}=V_{\mathrm{D}}-I_{\mathrm{D}}\left(R_{\mathrm{ACC}}-2 R_{\mathrm{C}}\right)
$$

where $R_{\mathrm{ACC}}$ and $R_{\mathrm{C}}$ are access region resistance and contact resistance, respectively, which are extracted by the transmission line method (TLM).

The $\mu$ was deteriorated by the $\gamma$-ray radiation and the $\mu$ maximum reduction $(\Delta \mu)$ was increased with an increase in the irradiated $\gamma$-ray doses. The $\mu$ is reduced from the low $2 \mathrm{DEG}$ density regime (inset in Figure 6a), which means that Coulomb scattering between the charges trapped in the interior of the gate insulator and electrons at the AlGaN/GaN interface gives rise to the mobility reduction. The $\mu$ deterioration ratio was around one-third in Sample- $\mathrm{HfO}_{2}$ compared to the Sample-SiN. The tendency of the $\Delta \mu$ corresponded to the $\Delta g_{\mathrm{m} \text {,max }}$ and $\Delta I_{\mathrm{D}}$ degradation. Therefore, the $\mu$ deterioration was the origin of the $g_{\mathrm{m}}$ and $I_{\mathrm{D}}$ reduction.

The sheet resistances of Sample-SiN and Sample- $\mathrm{HfO}_{2}$ were extracted by TLM before and after $\gamma$-ray radiation (data not shown). The sheet resistance was increased after the $\gamma$-ray irradiation due to the Coulomb scattering between the trapped charges inside the gate dielectric layer and electrons at the hetero-interface [23]. When the $\gamma$-ray irradiation dose increased, the sheet resistances of the 
two samples increased. The sheet resistances were 453 (Sample-SiN, before $\gamma$-ray radiation), 486 (Sample-SiN, after 3.6 Mrad $\gamma$-ray radiation), 451 (Sample- $\mathrm{HfO}_{2}$, before $\gamma$-ray radiation), and 467 (Sample- $\mathrm{HfO}_{2}$, after 3.6 Mrad $\gamma$-ray radiation) $\Omega / \square$. In Sample- $\mathrm{HfO}_{2}$, the deterioration of the sheet resistance was smaller compared to Sample-SiN.

Note that the contact resistance was also extracted via TLM. The extracted contact resistance values were 1.24 (Sample-SiN, before $\gamma$-ray radiation), 1.25 (Sample-SiN, after 3.6 Mrad $\gamma$-ray radiation), 1.26 (Sample- $\mathrm{HfO}_{2}$, before $\gamma$-ray radiation), and 1.24 (Sample- $\mathrm{HfO}_{2}$, after $3.6 \mathrm{Mrad} \gamma$-ray radiation) $\Omega \cdot \mathrm{mm}$. Therefore, the obvious damage to the metal electrodes caused by the $\gamma$-ray radiation was not achieved.

Based on the $\mu$ and sheet resistance deterioration trend with increasing irradiated $\gamma$-ray doses and less degradation of the $\mu$ and sheet resistance in Sample- $\mathrm{HfO}_{2}$ than in Sample-SiN, we can inversely verify that (i) the $\gamma$-ray irradiation resulted in the degradation of the gate dielectric quality and charge trapping inside the gate dielectric layer, and (ii) less charges are trapped in the $\mathrm{HfO}_{2}$ layer than in the $\mathrm{SiN}$ layer after the $\gamma$-ray irradiation. These results ensure that $\mathrm{HfO}_{2}$ shows enough strength to the $\gamma$-ray irradiation.

In Figure 7, the RF performance degradation generated by the $\gamma$-ray irradiation was also researched in GaN-based MIS-HEMTs. For the RF performance characterization, we first measured the $S$-parameter using the network analyzer. For the $f_{\mathrm{T}}$ extraction, the measured $S$-parameter was converted to the $H$-parameter. Then, we fitted a linear line with a $-20 \mathrm{~dB}$ slope on the $H 21$ curve. The extrapolated point of the linear line to the $0 \mathrm{~dB}$ should be $f_{\mathrm{T}}$. To obtain $f_{\mathrm{MAX}}$, the measured S-parameter was converted to be maximum stable gain (MSG)/maximum available gain (MAG). We fitted a linear line with a $-20 \mathrm{~dB}$ slope at stability factor $(\mathrm{K})=1$. Like the $f_{\mathrm{T}}$ extraction, the extrapolated point of the linear line to the $0 \mathrm{~dB}$ was defined as the maximum oscillation frequency.
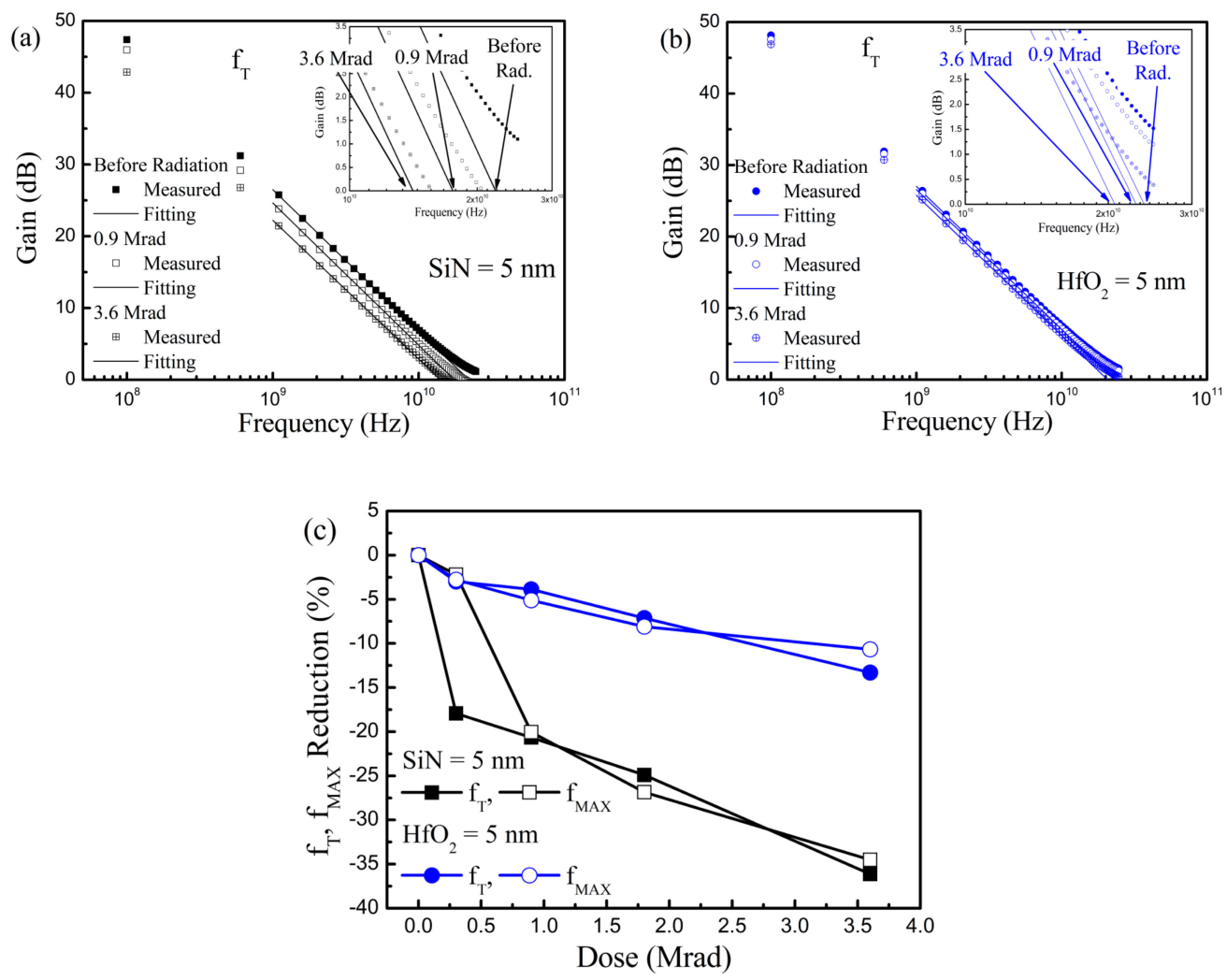

Figure 7. Radio frequency performance degradation induced by $\gamma$-ray radiation. Cut-off frequency characteristics before and after the $\gamma$-ray radiation in GaN-based MIS-HEMTs for a 5 nm-thick: (a) SiN; (b) $\mathrm{HfO}_{2}$ gate insulator. (c) Cut-off frequency and maximum oscillation frequency reduction vs. irradiated $\gamma$-ray doses. 
As we can anticipate from the DC performance alternation, the $f_{\mathrm{T}}$ and $f_{\mathrm{MAX}}$ deteriorated after the $\gamma$-ray radiation. After $\gamma$-ray radiation with doses of $3.6 \mathrm{Mrad}$, the $f_{\mathrm{T}}$ and $f_{\mathrm{MAX}}$ degradation rate was around three times larger when the $\mathrm{SiN}$ gate insulator was employed compared to the $\mathrm{HfO}_{2}$ gate dielectric layer. Therefore, the RF performance decrease was improved by using $\mathrm{HfO}_{2}$ as a gate dielectric layer. In comparison to the DC property deterioration, the RF performance degradation was larger. Note that further investigation is needed to figure out the reason of the relatively large RF performance degradation. One possible scenario is that the RF characteristics of the GaN-based MIS-HEMTs are more sensitive to the frequency response of the radiation-caused traps than the DC properties [24].

\section{Conclusions}

The device performance degradation mechanism of the GaN-based MIS-HEMTs induced by the $\gamma$-ray radiation was investigated through electrical device characterization, which was total ionizing dose effect generated at a great part of the gate insulator rather than the $\mathrm{AlGaN}$ barrier and GaN layers. According to the $\gamma$-ray irradiation, the gate insulator quality was deteriorated and the trapped charges inside the gate dielectric layer were increased. When the $\gamma$-ray was radiated, the preexisting defects known as $K$ centers were converted to positively charged $K^{+}$defects in the $\mathrm{SiN}$ gate insulator. In the $\mathrm{HfO}_{2}$ gate dielectric layer, the bond breaking was caused by the $\gamma$-ray irradiation and the oxygen vacancies of broken bonds trap holes. As a result, the device performance such as threshold voltage, transconductance, drain current, carrier mobility, and frequency characteristics was deteriorated. However, a huge improvement in the device performance degradation was achieved as the $\mathrm{HfO}_{2}$ was employed as a gate insulator due to its superior immunity to the $\gamma$-ray radiation. Compared to the $\mathrm{SiN}$ gate insulator, the threshold voltage shift, transconductance maximum deterioration, and drain current reduction were improved from 0.15 to $0.075 \mathrm{~V}, 5.42$ to $2.27 \%$, and 5.40 to $2.31 \%$, respectively, when $\mathrm{HfO}_{2}$ was used as the gate insulator. The RF performance degradation was also improved by employing the $\mathrm{HfO}_{2}$ gate insulator in comparison with the $\mathrm{SiN}$ gate dielectric layer. The cut-off frequency and maximum oscillation frequency degradation were improved from 36.14 to $13.3 \%$ and 34.52 to $10.68 \%$, respectively.

Author Contributions: Conceptualization, S.-J.C. and D.-S.K.; Investigation, S.-J.C., S.C.K., H.-W.J., and D.-S.K.; Data analysis, S.-J.C., D.-S.K., T.-W.K., J.-H.L., Y.B., H.K., Y.-S.N., S.-H.L., S.-I.K., H.-K.A., and J.-W.L.; Writing, S.-J.C. All authors have read and agreed to the published version of the manuscript.

Funding: This work was supported by the National Research Council of Science \& Technology (NST) grant by the Korean government (MSIP) (No. CRC-19-02-ETRI).

Conflicts of Interest: The authors declare no conflict of interest.

\section{References}

1. Kumar, V.; Lu, W.; Schwindt, R.; Kuliev, A.; Simin, G.; Yang, J.; Khan, M.A.; Adesida, I. AlGaN/GaN HEMTs on $\mathrm{SiC}$ with f/sub T/ of over $120 \mathrm{GHz}$. IEEE Electron Device Lett. 2002, 23, 455-457. [CrossRef]

2. Palacios, T.; Chakraborty, A.; Rajan, S.; Poblenz, C.; Keller, S.; DenBaars, S.P.; Speck, J.; Mishra, U.K. High-power AlGaN/GaN HEMTs for Ka-band applications. IEEE Electron Device Lett. 2005, 26, 781-783. [CrossRef]

3. Green, B.; Chu, K.; Chumbes, E.; Smart, J.; Shealy, J.; Eastman, L.F. The effect of surface passivation on the microwave characteristics of undoped AlGaN/GaN HEMTs. IEEE Electron Device Lett. 2000, 21, 268-270. [CrossRef]

4. Vetury, R.; Zhang, N.; Keller, S.; Mishra, U. The impact of surface states on the DC and RF characteristics of AlGaN/GaN HFETs. IEEE Trans. Electron Devices 2001, 48, 560-566. [CrossRef]

5. Eastman, L.F.; Tilak, V.; Smart, J.; Green, B.M.; Chumbes, E.M.; Dimitrov, R.; Kim, H.; Ambacher, O.S.; Weimann, N.; Prunty, T.; et al. Undoped AlGaN/GaN HEMTs for microwave power amplification. IEEE Trans. Electron Devices 2001, 48, 479-485. [CrossRef] 
6. Hashizume, T.; Kotani, J.; Hasegawa, H. Leakage mechanism in GaN and AlGaN Schottky interfaces. Appl. Phys. Lett. 2004, 84, 4884. [CrossRef]

7. Liu, Z.H.; Ng, G.I.; Arulkumaran, S.; Maung, Y.K.T.; Teo, K.L.; Foo, S.C.; Sahmuganathan, V. Improved tow-dimensional electron gas transport characteristics in $\mathrm{AlGaN} / \mathrm{GaN}$ metal-insulator-semiconductor high electron mobility transistor with atomic layer-deposited $\mathrm{Al}_{2} \mathrm{O}_{3}$ as gate insulator. Appl. Phys. Lett. 2009, 95, 223501. [CrossRef]

8. Ye, P.D.; Yang, B.; Ng, K.K.; Bude, J.; Wilk, G.D.; Halder, S.; Hwang, J.C.M. GaN metal-oxide-semiconductor high-electron-mobility-transistor with atomic layer deposited $\mathrm{Al}_{2} \mathrm{O}_{3}$ as gate dielectric. Appl. Phys. Lett. 2005, 86, 063501. [CrossRef]

9. Khan, M.; Hu, X.; Sumin, G.; Lunev, A.; Yang, J.; Gaska, R.; Shur, M. AlGaN/GaN metal oxide semiconductor heterostructure field effect transistor. IEEE Electron Device Lett. 2000, 21, 63-65. [CrossRef]

10. Chumbes, E.; Smart, J.; Prunty, T.; Shealy, J. Microwave performance of AlGaN/GaN metal insulator semiconductor field effect transistors on sapphire substrates. IEEE Trans. Electron Devices 2001, 48, 416-419. [CrossRef]

11. Hashizume, T.; Anantathanasarn, S.; Negoro, N.; Sano, E.; Hasegawa, H.; Kumakura, K.; Makimoto, $\mathrm{T}_{\text {. }} \mathrm{Al}_{2} \mathrm{O}_{3}$ Insulated-Gate structure for $\mathrm{AlGaN} / \mathrm{GaN}$ heterostructure field effect transistors having thin AlGaN barrier layers. Jpn. J. Appl. Phys. 2004, 43, L777-L779. [CrossRef]

12. Lee, C.T.; Chen, H.W.; Lee, H.Y. Metal-oxide-semiconductor using $\mathrm{Ga}_{2} \mathrm{O}_{3}$ dielectrics on n-type GaN. Appl. Phys. Lett. 2003, 82, 4304. [CrossRef]

13. Liu, C.; Chor, E.F.; Tan, L.S. Investigations of $\mathrm{HfO}_{2} / \mathrm{AlGaN} / \mathrm{GaN}$ metal-oxide-semiconductor high electron mobility transistors. Appl. Phys. Lett. 2006, 88, 173504. [CrossRef]

14. Mehandru, R.; Luo, B.; Kim, J.; Ren, F.; Gila, B.P.; Onstine, A.H.; Abernathy, C.R.; Pearton, S.J.; Gotthold, D.; Birkhahn, R.; et al. AlGaN/GaN metal-oxide-semoconductor high electron mobility transistors using $\mathrm{Sc}_{2} \mathrm{O}_{3}$ as the gate oxide and surface passivation. Appl. Phys. Lett. 2003, 82, 2530. [CrossRef]

15. Balachander, K.; Arulkumaran, S.; Ishikawa, H.; Baskar, K.; Egawa, T. Studies on electron beam evaporated $\mathrm{ZrO}_{2} / \mathrm{AlGaN} / \mathrm{GaN}$ metal-oxide-semiconductor high-electron-mobility transistors. Phys. Status Solidi 2005, 202, R16-R18. [CrossRef]

16. Chang, S.J.; Jung, H.W.; Do, J.W.; Cho, K.J.; Kim, J.J.; Jang, Y.J.; Yoon, H.S.; Ahn, H.K.; Min, B.G.; Kim, H.; et al. Enhanced carrier transport properties in GaN-Based metal-insulator-semiconductor high electron mobility transistor with $\mathrm{SiN} / \mathrm{Al}_{2} \mathrm{O}_{3}$ Bi-layer passivation. ECS J. Solid State Sci. Technol. 2018, 7, N86-N90. [CrossRef]

17. Anand, M.J.; Ng, G.I.; Vicknesh, S.; Arulkumaran, S.; Ranjan, K. Reduction of current collapse in AlGaN/GaN MISHEMT with bilayer $\mathrm{SiN} / \mathrm{Al}_{2} \mathrm{O}_{3}$ dielectric gate stack. Phys. Status Solidi 2013, 10, 1421-1425.

18. Keum, D.; Kim, H. Energy-dependent degradation characteristics of AlGaN/GaN MIS-HEMTs with 1, 1.5, and $2 \mathrm{MeV}$ proton irradiation. ECS J. Solid State Sci. Technol. 2018, 7, Q159-Q163. [CrossRef]

19. Sun, X.; Saadat, O.I.; Chen, J.; Zhang, E.X.; Cui, S.; Palacios, T.; Fleetwood, D.M.; Ma, T.P. Total-ionizing-dose effects in AlGaN/GaN HEMTs and MOS-HEMTs. IEEE Trans. Nucl. Sci. 2013, 60, 4074-4079. [CrossRef]

20. Ahn, S.; Kim, B.J.; Lin, Y.H.; Ren, F.; Pearton, S.; Yang, G.; Kravchenko, I.I. Effect of proton irradiation dose on InAlN/GaN metal-oxide semiconductor high electron mobility transistors with $\mathrm{Al}_{2} \mathrm{O}_{3}$ gate oxide. J. Vac. Sci. Technol. B 2016, 34, 051202. [CrossRef]

21. Bhuiyan, M.A.; Zhou, H.; Chang, S.J.; Lou, X.; Gong, X.; Jiang, R.; Gong, H.; Zhang, E.X.; Won, C.; Lim, J.W.; et al. Total-Ionizing-Dose responses of GaN-Based HEMTs with different channel thicknesses and MOSHEMTs with epitaxial MgCaO as gate dielectric. IEEE Trans. Nucl. Sci. 2018, 65, 46-52. [CrossRef]

22. Gao, Z.; Romero, M.F.; Redondo-Cubero, A.; Pampillon, M.A.; Andrés, E.S.; Calle, F. Effects of $\mathrm{Gd}_{2} \mathrm{O}_{3} \mathrm{Gate}$ dielectric on proton-irradiated AlGaN/GaN HEMTs. IEEE Electron Device Lett. 2017, 38, 611-614. [CrossRef]

23. Chang, S.J.; Cho, K.J.; Jung, H.W.; Kim, J.J.; Jang, Y.J.; Bae, S.B.; Kim, D.S.; Bae, Y.; Yoon, H.S.; Ahn, H.K.; et al. Improvement of proton radiation hardness using ALD-Deposited $\mathrm{Al}_{2} \mathrm{O}_{3}$ gate insulator in GaN-Based MIS-HEMTs. ECS J. Solid State Sci. Technol. 2019, 8, Q245-Q248. [CrossRef]

24. Aktas, O.; Kuliev, A.; Kumar, V.; Schwindt, R.; Toshkov, S.; Costescu, D.; Stubbins, J.; Adesida, I. ${ }^{60}$ Co gamma radiation effects on DC, RF, and pulsed I-V characteristics of AlGaN/GaN HEMTs. Solid-State Electron. 2004, 48, 471-475. [CrossRef]

25. Kaya, S.; Yildiz, I.; Lok, R.; Yilmaz, E. Co-60 gamma irradiation influences on physical, chemical and electrical characteristics of $\mathrm{HfO}_{2} / \mathrm{Si}$ thin films. Radiat. Phys. Chem. 2018, 150, 64-70. [CrossRef] 
26. Suria, A.J.; Chiamori, H.C.; Shankar, A.; Senesky, D.G. Capacitance-voltage characteristics of gamma irradiated $\mathrm{Al}_{2} \mathrm{O}_{3}, \mathrm{HfO}_{2}$, and $\mathrm{SiO}_{2}$ thin films grown by plasma-enhanced atomic layer deposition. In Sensors for Extreme Harsh Environments II, Proceedings of SPIE Vol.; Senesky, D.G., Dekate, S., Eds.; 9491, Baltimore, MD, USA, 20-24 April 2015; Senesky, D.G., Dekate, S., Eds.; SPIE: Bellingham, WA, USA, 2015, p. 949105.

27. Chang, S.J.; Bhuiyan, M.A.; Won, C.H.; Lee, J.H.; Jung, H.W.; Shin, M.J.; Lim, J.W.; Ma, T.P. Dependence of GaN channel thickness on the transistor characteristics of AlGaN/GaN HEMTs grown on sapphire. ECS J. Solid State Sci. Technol. 2016, 5, N102-N107. [CrossRef]

28. Krick, D.T.; Lenahan, P.M.; Kanicki, J. Nature of the dominant deep trap in amorphous silicon nitride. Phys. Rev. B 1988, 38, 8226-8229. [CrossRef]

29. Hezel, R.; Schorner, R. Plasma Si nitride-A promising dielectric to achieve high-quality silicon MIS-IL solar cells. J. Appl. Phys. 1981, 52, 3076-3079. [CrossRef]

30. Sharma, V.; Tracy, C.J.; Schroder, D.K.; Herasimenka, S.; Dauksher, W.J.; Bowden, S. Manipulation of K center charge states in silicon nitride films to achieve excellent surface passivation for silicon solar cells. Appl. Phys. Lett. 2014, 104, 053503. [CrossRef]

31. Dong, P.; Yu, X.; Ma, Y.; Xie, M.; Li, Y.; Huang, C.; Li, M.; Dai, G.; Zhang, J. A deep-level transit spectroscopy study of gamma-ray irradiation on the passivation properties of silicon nitride layer on silicon. AIP Adv. 2017, 7, 085112. [CrossRef]

32. Chang, S.J.; Kang, H.S.; Lee, J.H.; Yang, J.; Bhuiyan, M.; Jo, Y.W.; Cui, S.; Lee, J.H.; Ma, T.P. Investigation of channel mobility in AlGaN/GaN high-electron-mobility transistors. Jpn. J. Appl. Phys. 2016, 55, 44104. [CrossRef]

Publisher's Note: MDPI stays neutral with regard to jurisdictional claims in published maps and institutional affiliations. 